\title{
Effects of a parent training programme for the treatment of young children with separation anxiety disorder
}

\author{
Sandra Mayer-Brien ${ }^{1}$, Lyse Turgeon ${ }^{2 *}$ and Marc J. Lanovaz ${ }^{2}$ \\ ${ }^{1}$ Département de psychologie, Université de Montréal, Case postale 6128, Succursale Centre-Ville, \\ Montréal (Québec), Canada, H3C $3 J 7$ \\ ${ }^{2}$ École de psychoéducation, Université de Montréal, Case postale 6128, Succursale Centre-Ville, \\ Montréal (Québec), Canada, H3C $3 J 7$
}

Received 20 April 2017; Accepted 11 October 2017

\begin{abstract}
Cognitive behavioural therapy (CBT) has been shown to be an effective treatment for anxiety disorders in children. However, the majority of studies conducted to date have included heterogeneous samples of children combining social anxiety disorder, generalized anxiety disorder and separation anxiety disorder (SAD) together. Few studies have examined the efficacy of CBT to specifically treat SAD. Moreover, research on the impact of CBT for SAD in children younger than 7 years old has been very limited. To address these issues, we examined the effects of a CBT parent training programme with six children with SAD aged between 4 and 7 years using a non-concurrent multiple baseline design. Parents completed semi-structured interviews, questionnaires and daily diaries to assess their child's anxiety symptoms, parental practices and parental stress. Results indicated that five of six children no longer met the criteria for SAD diagnosis after treatment and at 3-month follow-up. Moreover, the daily diaries showed that four of six children presented a systematic favourable change of the total weekly frequency of SAD symptoms. Finally, four mothers reported a decrease in overprotection, but we observed no changes in parental stress.
\end{abstract}

Key words: anxiety disorders, behavioural family intervention, CBT, single case experimental design, childhood anxiety

\section{Introduction}

The main feature of separation anxiety disorder (SAD) in children is an excessive and persistent fear of leaving home or to be separated from attachment figures, most frequently a parent (American Psychiatric Association, 2013). Epidemiological studies indicate that 2-5\% of children have SAD (Carter et al., 2010; de la Barra et al., 2014; Lavigne et al., 2009). A recent study shows a prevalence as high as $10 \%$ among preschool children (2-5 years old) recruited in first-line pediatric clinics (Franz et al., 2013). Furthermore, Shear et al. (2006) found that $36 \%$ of cases persist until adulthood. Having a SAD may have a negative impact

\footnotetext{
*Author for correspondence: Lyse Turgeon, École de psychoéducation, Université de Montréal, Case postale 6128, Succursale Centre-Ville, Montréal (Québec) CANADA H3C 3J7 (E-mail: lyse.turgeon@ umontreal.ca).
}

(C) British Association for Behavioural and Cognitive Psychotherapies 2017 
on children and their families. For example, researchers have shown that children with SAD are more susceptible to experience sleep problems (Chase and Pincus, 2011) and to exhibit school refusal (Last et al., 1987). By avoiding situations associated with separation, children with SAD may also fail to participate in activities, such as birthday parties, sporting events or summer camps, which can in turn interfere with adaptation and lead to social isolation (Ehrenreich et al., 2008; Figueroa et al., 2012). In the long term, SAD is associated with an increased risk of developing psychological disorders during adolescence and adulthood, such as other anxiety disorders and depression (Biederman et al., 2007; Lewinsohn et al., 2008). Given the high prevalence of SAD, its undesirable side-effects and its persistence, early detection and treatment appear essential.

Children who have insecure attachment with their parents are more likely to develop SAD during childhood (Brumariu and Kerns, 2010a,b; Mofrad et al., 2009; Mofrad et al., 2010). In contrast, secure attachment may protect against and prevent the development of SAD (Bögels and Brechman-Toussaint, 2006). Other studies have outlined the role of parental stress in the development of internalizing disorders, including SAD (Pahl et al., 2012). In the same vein, Costa et al. (2006) have shown that dysfunctional parent-child interactions, a component of parental stress, was specifically related to internalizing symptoms in children. Furthermore, researchers have also found that negative and controlling parental practices are associated with the development of anxiety disorders (Bögels and Brechman-Toussaint, 2006; McLeod et al., 2011; Wood et al., 2003).

Parental control in the form of overprotection, overinvestment and intrusiveness may be particularly damaging (McLeod et al., 2011). For example, Mofrad et al. (2009) have shown that there is a relationship between SAD and maternal overprotection. Similarly, Wood (2006) has demonstrated that parental intrusiveness may be associated with the development of SAD. The influence of attachment style and parental practices on the development and maintenance of SAD underlines the importance of intervening on the parent-child relationship during treatment. As such, it seems relevant to include treatment components designed to improve the quality of attachment, to increase parental sensitivity, emotional warmth and positive interactions as well as to reduce control and overprotection.

Many studies have shown the efficacy of cognitive behaviour therapy (CBT) in the treatment of anxiety disorders in children (for reviews, see Reynolds et al., 2012; Silverman et al., 2008). CBT typically helps the child to recognize anxious feelings and somatic reactions to anxiety, to modify anxious self-talk, and to develop a plan to cope with anxiety-evoking situations. Some studies have shown that the participation of parents in treatment increases the efficacy of CBT interventions for children with anxiety disorders (Barrett et al., 1996; Wood et al., 2006). Moreover, parent-only CBT is an effective treatment modality for child anxiety (Smith et al., 2014). Parent-focused intervention was also found to be an optimal strategy at lower economic costs compared with child-focused intervention (Simon et al., 2012). In sum, research on the treatment of anxiety disorders in children has shown that CBT is a cost-effective treatment option when it is implemented directly by the parent.

It should be noted that the previous treatment studies were not developed specifically for children with SAD, but instead targeted general forms of anxiety. To date, only four programmes for SAD focusing on parental participation have been developed and assessed in randomized clinical trials or single-case studies: (1) the Parent Training Treatment for Separation-Anxious Children (PT-SAD; Raleigh et al., 2002), (2) the Parent-Child Interaction Therapy (PCIT; Pincus et al., 2005), (3) the Child Anxiety Multi-Day Program (CAMP; 
Santucci et al., 2009), and (4) the Separation Anxiety Family Treatment Program (PFAS; Blatter-Meunier and Schneider, 2011). The PT-SAD is a CBT programme targeting parents of children aged between 6 and 12 years old diagnosed with SAD (Raleigh et al., 2002). The main objective of the programme is to develop parental skills to cope with the child's anxiety symptoms, such as contingency management, relaxation and exposure. Eisen et al. (2008) examined the efficacy of the programme using single-case designs with six parents of children aged from 7 to 10 years old with SAD. Following the intervention, five children no longer met the criteria for the diagnosis of SAD.

Pincus and her colleagues (Pincus et al., 2005; Pincus et al., 2008) have adapted a programme initially developed for oppositional behaviours, the PCIT (Brinkmeyer and Eyberg, 2003), to treat symptoms of SAD. The main objective of the programme is to increase attachment and emotional warmth between the parent and the child in order to improve the child's confidence and to reduce distress when separation occurs. To meet these objectives, parents are taught various strategies, such as providing positive attention in the form of praise and avoiding criticisms (Choate et al., 2005). The PCIT programme also has the objective of teaching the parent effective strategies to decrease the child's anxiety. For example, the parent should reinforce the child's appropriate separation behaviours while ignoring tantrums and requests for reassurance. Pincus et al. (2005) first tested the efficacy of PCIT in a pilot study with 10 families of children aged from 4 to 8 years old having SAD. Following treatment, parents reported an increase in the use of positive strategies. A decrease in anxiety symptoms among children was also reported; however, these symptoms remained within the clinical range. The authors subsequently added another treatment phase, the Bravery-Directed Interaction phase, to specifically target anxiety. This phase consisted mainly of exposure exercises guided by the parents. Pincus et al. (2008) assessed the efficacy of the modified PCIT in a clinical trial with 38 families. Results showed that $73 \%$ of the children who received the modified PCIT did not meet the SAD diagnostic criteria following intervention.

Santucci et al. (2009) have developed an intensive one-week programme in a group format to treat SAD. The CAMP is a CBT-based programne that includes conjoint parent-child sessions as well as separate, individual sessions. Santucci et al. first assessed the efficacy of the CAMP programme in a pilot study with five girls aged from 8 to 11 years old, which showed promising results. In a subsequent randomized clinical trial, Santucci and EhrenreichMay (2013) assessed the efficacy of the programme with 29 school-aged girls (7-12 years). Six weeks after the intervention, $61 \%$ of the girls no longer met the diagnostic criteria for SAD.

Finally, the PFAS (Blatter-Meunier and Schneider, 2011) was developed in Switzerland and Germany. The programme targets children from 5 to 13 years old having SAD as well as their parents. It includes CBT components such as education on anxiety symptoms, cognitive strategies (i.e. self-instruction for children and cognitive restructuring of dysfunctional thoughts concerning the child's anxiety for the parents) as well as exposure. A parent training component is also included, in which the parents learn strategies to help their child cope with anxiety. The efficacy of the programme has been assessed with 43 children aged from 5 to 7 years old and their families, randomly assigned either to the treatment condition or to a 12-week wait-list control condition (Schneider et al., 2011). The results showed that $76 \%$ of the children from the treatment condition no longer met the diagnostic criteria of SAD after treatment, compared with $14 \%$ of those from the wait-list condition. 
The purpose of our study was to replicate and extend previous research on the treatment of SAD in young children. The first objective was to examine the effects of a parent training programme on separation anxiety symptoms among young children aged between 4 and 7 years old. This age group has received less attention in the research literature, even though SAD typically appears at this stage of development. Given that interfering symptoms may be evident as early as age 3 (Kearny et al., 2003), the lack of empirically supported treatments for this age group may result in the use of age-inappropriate and untested treatments (Pincus et al., 2008). Early intervention in preschool or in the first years of elementary school would also have the advantage of decreasing the risk of negative consequences associated with SAD, such as school refusal and social difficulties. The second objective was to examine the effects of the programme on parental practices, such as overprotection and control, as well as on parental stress. We chose the PT-SAD (Raleigh et al., 2002) because our purpose was to test a weekly programme that targeted parents. We also added a relational component from the PCIT (Pincus et al., 2005) to improve the parent-child relationship and to decrease negative parental practices. Finally, the third objective was to examine if the changes reported by the parents were also observed by the teachers in other settings.

\section{Method}

\section{Participants}

Fifteen families participated in an initial assessment session. From these families, seven were excluded because (a) the child's SAD symptoms were not clinically significant, (b) the child had another primary disorder (other than SAD), or (c) the parent could not complete the daily records. Two families withdrew their participation during treatment: one moved to another city and the other was preoccupied with stressful life events. The final sample included six parentchild dyads: four boys and two girls. The children were between 4 and 7 years old (mean: 5 years and 7 months) and had a primary diagnosis of SAD according to the DSM-IV-TR criteria (American Psychiatric Association, 2000) with at least moderate impairment (received 4 or more) on the Anxiety Disorders Interview Schedule for DSM-IV-Parent version (ADIS-P; Silverman and Albano, 1996). We only invited children who were not taking medication for anxiety and whose dosage for other medications was stable 3 months prior to and during the study. Parent-child dyads were recruited through day care centres, community organizations, local newspaper advertisements, and parenting websites.

Participant 1 (P1) was a boy of both Hispanic and Caucasian origins who was 4 years and 7 months at the onset of his participation in the study. His symptoms were mainly related to bedtime. He slept with his parents every night. Each morning, he refused to go to day care. He asked to stay home, clung to his mother, cried, or had temper tantrums. He worried that his mother would die. He often sought her physical contact. His mother was a 39-year-old immigrant who worked a few hours per week in a community agency. His father was a 40year-old Caucasian working in the construction industry.

Participant 2 (P2) was a Caucasian girl who was 4 years and 8 months old. Her main symptoms also occurred at bedtime. She slept with her mother because she was afraid of being alone in the dark. She also refused that her mother drop her off at the day care centre in the morning. She constantly followed her mother around in their home, and she asked for a 
lot of attention. She also had specific phobias related to darkness, doctors and injections. Her mother was a 45-year-old single parent who was unemployed.

Participant 3 (P3) was a Caucasian girl who was 7 years and 9 months old. She was in second grade. Her separation anxiety symptoms were mainly related to her refusal to go to events without her parents (e.g. birthday parties). She worried that bad things would happen to her mother, or that her mother would abandon her. She often asked her parents to stay with her at bedtime. She also had symptoms of social anxiety, a specific phobia of vomiting, and she had concerns regarding her health and her family members' health. Her mother was a 47-year-old worker in the service industry and her father was a 44-year-old professional.

Participant 4 (P4) was a Caucasian boy who was 6 years and 6 months old. He was in first grade. His anxiety symptoms were related to being alone, to leaving for school in the morning, and to uncontrolled fears (e.g. his parents dying in an accident). When he went to bed, he always repeated the same ritual: he asked his parents to lie down next to him and tried to postpone their departure. $\mathrm{P} 4$ had symptoms of generalized anxiety disorder, social anxiety and a specific phobia of thunderstorms. He was diagnosed with attention-deficit disorder for which he took a stable dosage of Concerta. His mother was a 34-year-old educator and his father was a 35-year-old manager.

Participant 5 (P5) was a Caucasian boy who was 4 years and 4 months old. He showed anxiety in all settings where he was separated from his mother, including day care, and followed her excessively around the house for physical contact. He also showed symptoms of social anxiety and specific phobias (i.e. water and darkness) as well as oppositional behaviours. His mother was a 30 -year-old student and his father was a 35 -yearold professional.

Participant 6 (P6) was a Hispanic boy who was 5 years and 8 months old. His separation anxiety occurred when his mother dropped him off at school or when he had to go to events without his parents (e.g. friend's house, birthday party). He often complained of stomach pain before leaving for school; he occasionally vomited. He also displayed specific phobias related to blood, injections and wounds. His mother was a 36-year-old part-time worker in the service industry and his father was a 36-year-old manager.

\section{Measures}

Measures completed by the parents. Each child's diagnosis of SAD was based on the DSMIV-TR criteria of the ADIS-P (Silverman and Albano, 1996). The ADIS-P is the most commonly used parental interview to assess anxiety disorders among children (Silverman et al., 2001). Studies on its psychometric properties have shown that it has an excellent testretest reliability and a good convergent validity (Silverman et al., 2001; Wood et al., 2002). In the present study, we administered the French translation (Turgeon and Brousseau, 2001). The first author, a doctoral student in psychology, administered the ADIS-P. The second author, an expert clinical researcher on anxiety disorders in children, looked at the videotape of the interviews with the first author to confirm the initial diagnosis.

The parents completed the Daily Record of Anxiety at Separation or Daily Diary (DD), translated into French and adapted from the Weekly Record of Anxiety at Separation (Choate and Pincus, 2001) (see Appendix). In the current study, observations were collected on a daily basis rather than on a weekly basis. Parents had to record the intensity of each anxiety behaviour on a scale from 0 to $8(0=$ no anxiety, $8=$ high anxiety). Examples of items 
included statements such as 'refused to go to day care and to be separated from his parent', or 'slept in the parents' bed'. We added an interference measure in the DD, in which parents had to assess how the child's symptoms interfered with daily functioning, also on a scale from 0 to 8 . The parents completed the DD every day during baseline and during the course of treatment. At post-treatment and at 3-month follow-up, the parents also completed the DD for one or two weeks. For five families, only the mother completed the DD. For the remaining family (i.e. P4), both parents completed the diary either together or in alternation.

We also administered questionnaires to the parents. First, the parents completed the Preschool Anxiety Scale (PAS; Spence and Rapee, 1999), which is used to assess anxiety symptoms in children, including SAD. Spence et al. (2001) have shown that the instrument has good construct validity, and Broeren and Muris (2008) reported an internal consistency from 0.59 to 0.86 for the various subscales. We used the French version as part of the current study (Turgeon and Brousseau, 2002). Second, the Parenting Practices Interview (PPI; Webster-Stratton, 1998) was used to assess parental practices. Two subscales of the PPI were selected: 'harsh and inconsistent discipline' and 'praise and incentives'. The French translation used in the current study showed a good internal consistency, 0.83 for harsh and inconsistent discipline, and 0.69 for praise and incentives (Lessard, 2010). Third, the Parent Protection Scale (PPS; Thomasgard et al., 1995) was administered in French to assess protection behaviours in our sample of parents. Thomasgard et al. (1995) have shown that the instrument has good internal consistency (0.73), good test-retest reliability (0.86 after 3-5 weeks) and criterion validity. Finally, the Parenting Stress Index-Brief Form (PSI; Abidin, 1995) assessed stress related to parent-child relation and to parental role. Three scores were used: total score, parental distress, and dysfunctional parent-child relation. The PSI shows good internal consistency ( 0.91 for the total score) and excellent test-retest reliability (Abidin, 1995). It has been translated into French by Bigras et al. (1996). The parents completed these questionnaires at pre-test, post-test, and at 3-month follow-up.

Measures completed by the teachers. The teachers completed the 'Anxiety problems' subscale of the Teacher Report Form (TRF; Achenbach and Rescorla, 2001). The TRF shows good internal consistency (0.73) and good test-retest reliability (0.73 at 16 days; Achenbach and Rescorla, 2001). They also completed the 'Anxiety separation' subscale of the Preschool Anxiety Scale-Teacher Version (PAS-T; Spence and Rapee, 1999) and the Socio-Affective Profile (PSA; Dumas et al., 1997). In the current study, we used two general scores (general adaptation and internalized problems) and two subscales (anxious-confident and dependentindependent) of the PSA. The PSA has good psychometric properties, including discriminant and convergent validity, internal consistency and test-retest reliability (Venet et al., 2002). The teachers were recruited through the parents. The investigators of the study sent questionnaires to preschool or school at three time points: during baseline, immediately after treatment, and at 3-month follow-up. All teachers accepted to complete the questionnaires, except at post-test for P1 and P4. For P3, P4 and P5, a different person completed the questionnaire at 3-month follow-up, because these children changed academic level between administrations.

\section{Procedure}

Due to recruitment issues (i.e. the participants were not available at the same time to start treatment because the recruitment took more than a year), we used a non-concurrent multiple 
baseline across participants (Barlow et al., 2009). To begin, the first author contacted the parents who responded to the advertisements in order to validate whether their child met the inclusion and exclusion criteria. Then the parents were invited to a first session during which the researcher (first author) explained the project and sought written, informed consent. In the second half of the session, we administered the ADIS-P to the parents. Questionnaires were then given to the parents to be completed at home and returned at the beginning of the following session. During the second session, the researcher explained how to complete the DD. Parents could either return their DD by mail or by email during baseline. Parents were contacted once per week by telephone or by email during baseline to encourage them to complete their DD accurately and to respond to any questions. The project was approved by the Ethics Committee of the University where the research was conducted.

\section{Baseline}

During baseline, the parents recorded the child's anxiety symptoms on a daily basis by means of the DD. Baselines of 2, 3 or 4 weeks were randomly assigned to each dyad. However, we did not begin treatment unless levels of anxiety symptoms were stable or increasing. We used visual inspection of the graphs to determine if symptoms were stable. If it was not the case, we instructed the parents to continue collecting baseline data. Two families started treatment after 3 weeks of baseline, three families after 4 weeks, and one family after 8 weeks due to a 2-week holiday break.

\section{Treatment}

The treatment programme was a modified version of the Parent Training Treatment Manual for Separation-Anxious Children (Raleigh et al., 2002) adapted for parents of children aged from 4 to 7 years old. To adapt the programme for young children, we removed cognitive strategies such as cognitive restructuring and we modified relaxation training with shorter and playful exercises from the FRIENDS programme (Barrett et al., 1999). We also included components of the PCIT (Pincus et al., 2005) focusing on emotional warmth and sensitivity in parent-child interactions. Each session involved the same four steps as the original Parent Training Treatment Manual for Separation-Anxious Children. First, the parent and trainer reviewed the DD and the exercises practised during the previous week. Second, the trainer presented new strategies. Third, the parents practised these new strategies with feedback from the trainer. Finally, the trainer explained the exercises that the parent and child should practise during the following week.

During sessions 1 and 2, the trainer presented the characteristics and aetiology of SAD and discussed frequent errors made by parents. Session 3 aimed to teach parents strategies to increase emotional warmth in the parent-child relationship (e.g. praising, reflections, avoidance of criticisms). These strategies were first practised in role play during sessions, and then applied at home with the child during play sessions. Sessions 4 to 6 targeted the development of strategies to cope with their child's anxiety: in vivo exposure, relaxation training and contingency management. Sessions 7 and 8 were the practice phase of the programme, during which the parents guided their children in their exposure exercises at home and applied the other learned strategies. Finally, the purpose of sessions 9 and 10 was to maintain acquired skills through the use of problem-solving strategies and to promote 
generalization of the behaviour changes. The therapist (first author) was a $\mathrm{PhD}$ student in clinical psychology, supervised by an experienced clinical psychologist specialized in the CBT treatment of childhood anxiety disorders (second author). Mothers and fathers were encouraged to participate in the treatment sessions, but only one father was present (P4).

\section{Treatment integrity}

The researcher audiotaped the therapy sessions in order to verify treatment integrity. For each session, a coder listened to the tape and noted if each content area was covered. Treatment integrity was calculated for each session by dividing the number of content areas that were covered by the total number of content areas that should have been presented. The mean percentage of content presented ranged from 94 to $99 \%$ across participants.

\section{Post-test and follow-up}

Following the last treatment session, we provided the same questionnaires as baseline to complete at home, and we instructed the parents to complete the DD for 2 weeks. The mother of P2 did not complete the DD because she was not available at this time. Two weeks following the end of treatment, parents met with an independent evaluator (a PhD student in psychology) who administered the ADIS-P for a second time. Three months later, parents were contacted and instructed to complete DD for 1 to 2 weeks. We administered the same questionnaires as baseline and post-test. Only the sections of the ADIS-P corresponding to the child's pre-test and post-test symptoms were administered.

\section{Data analysis}

Given the variability in the manifestation of separation anxiety symptoms and the large amount of data collected, we used the data from the DD to compute a weekly frequency of separation anxiety symptoms. For each child, we only present the results of anxiety symptoms that had a mean weekly intensity of at least 4 during baseline, a mean weekly frequency of at least 3 , or both. To assess changes in symptoms from baseline to intervention, we used the conservative dual-criterion method of analysis (CDC; Fisher et al., 2003; Swoboda et al., 2010), which is based on changes in slope and mean. Specifically, the CDC examines the number of treatment data points that fall below both a mean line and a trend line continued from baseline, which have been lowered by 0.25 standard deviations. The number of points that need to fall below both lines for the treatment to be considered significant is based on the total number of treatment data points and on the binomial distribution.

For the PAS completed by the parents, we considered a change as significant when the scores at post-test and at 3-month follow-up were larger than one standard deviation from the normative mean of the questionnaire and the functioning level was in the non-clinical range. For parental practices and teacher-reported measures, we considered a change significant when the results met the two following conditions: (a) the score was in the non-clinical range at post-test and at 3-month follow-up as determined by the clinical cut-off point of the instrument, and (b) the change was large enough that it was unlikely to be due to measurement error as determined by the RC reliable change index (Thomas and Truax, 2008). Given that a clinical cut-off point was not available for two subscales (distress scale and the dysfunctional 

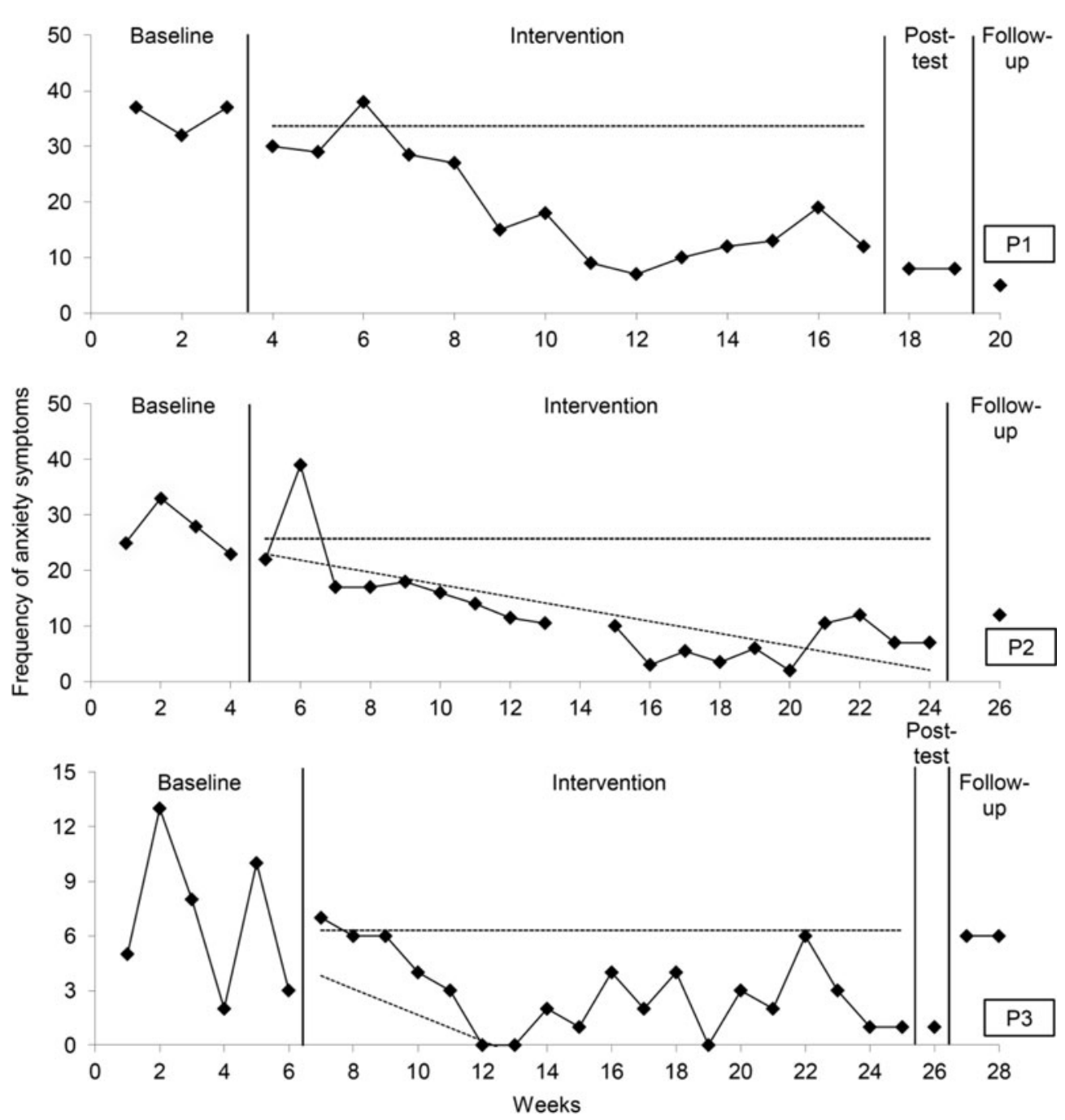

Figure 1. Frequency of separation anxiety symptoms during baseline, intervention, post-test and followup for P1, P2 and P3. Note that for P1 the mean and trends line are the same.

relation scale) of the PSI a B score was calculated (Jacobson and Truax, 1991), which corresponded to a change greater than two standard deviations from the mean of the nonclinical population.

\section{Results}

\section{Daily diaries}

Figures 1 and 2 present the weekly frequency of separation anxiety symptoms for each child with the conservative mean and trend lines from baseline. According to the CDC analysis of 

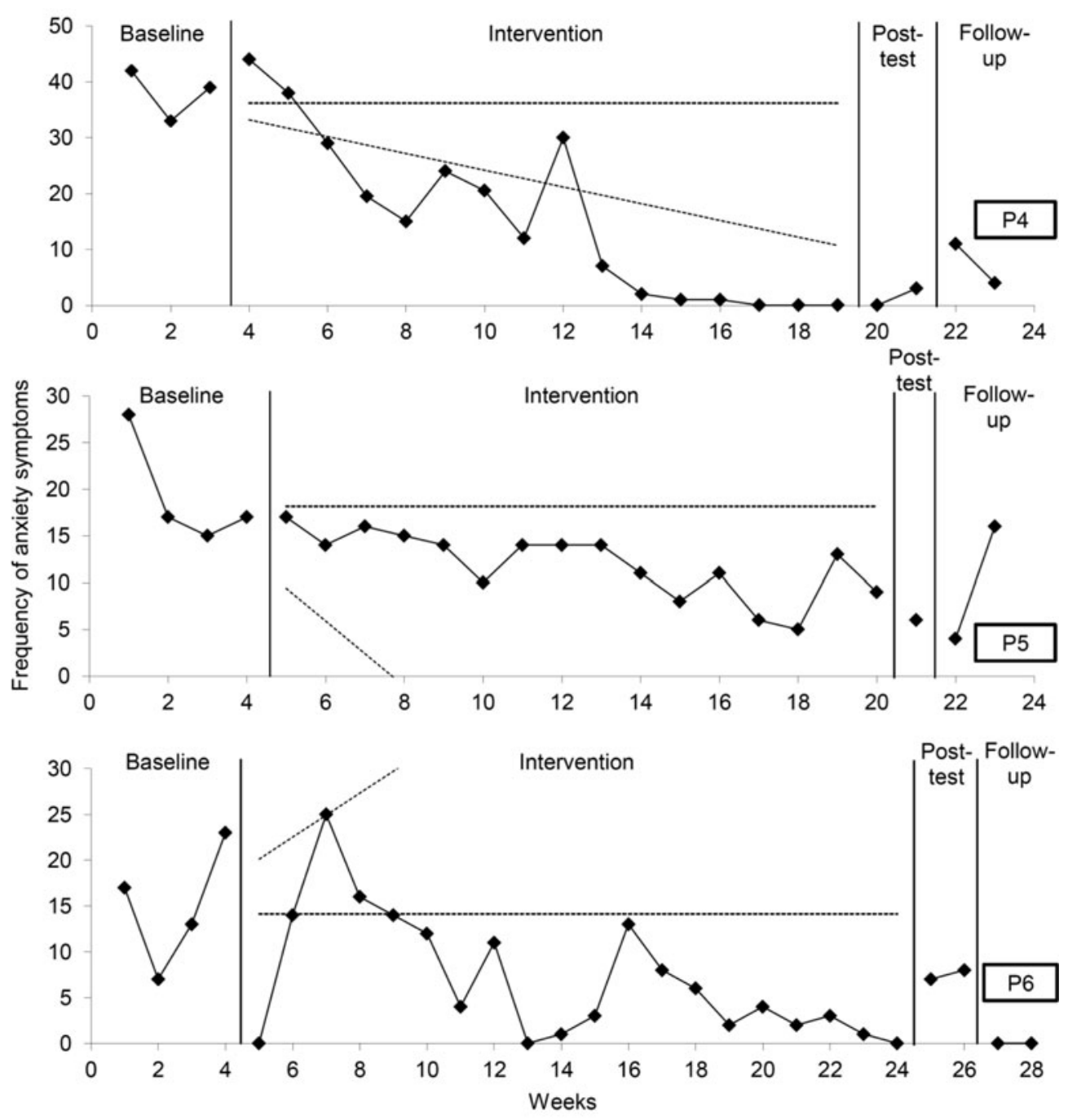

Figure 2. Frequency of separation anxiety symptoms during baseline, intervention, post-test and followup for P4, P5 and P6.

the DD completed by the parents, we can conclude that there was a systematic change of the weekly frequency for symptoms between baseline and intervention for four participants: P1, P2, P4 and P6.

\section{SAD diagnosis}

Following treatment, five of six children no longer met the SAD diagnostic criteria according to the parent ratings on the ADIS-P. These changes persisted at 3-month follow-up. At posttest, scores on the ADIS-P changed from 8 to 0 for P1, 6 to 3 for P2, 8 to 0 for $\mathrm{P} 4,7$ to 1 for 
Table 1. Results of the Parental Preschool Anxiety Scale

\begin{tabular}{lclllcl}
\hline Participant & Pre & Post & Follow-up & Clinical cut-off & Pre-post change & Pre-follow-up change \\
\hline P1 & 14 & $1^{a b}$ & $3^{a b}$ & 5.58 & $\mathbf{- 4 . 6}$ & $\mathbf{- 3 . 9}$ \\
P2 & 9 & 8 & $6^{b}$ & 5.58 & -0.4 & $\mathbf{- 1}$ \\
P3 & 8 & 10 & 8 & 5.58 & 0.7 & 0 \\
P4 & 18 & $2^{a b}$ & $2^{a b}$ & 5.58 & $\mathbf{- 5 . 6}$ & $\mathbf{- 5 . 6}$ \\
P5 & 12 & 10 & 12 & 5.58 & -0.7 & 0 \\
P6 & 8 & $2^{a b}$ & $3^{a b}$ & 5.58 & $\mathbf{- 2 . 1}$ & $\mathbf{- 1 . 8}$ \\
\hline
\end{tabular}

The last two columns indicate changes as measured in standard deviations (SD). Positive values show an increase in symptoms. Changes greater than $1 \mathrm{SD}$ are indicated in bold. ${ }^{a}$ Score in non-clinical range; ${ }^{b}$ improvement of at least 1 SD from pre-test.

P5, and 6 to 3 for P6. P3 still met the SAD diagnostic criteria, but the severity score decreased from 6 to 4 .

\section{Parent-reported child anxiety symptoms}

Table 1 presents the scores for the separation anxiety symptoms on the parental PAS. Results showed a significant change for three children at posttest and at 3-month follow-up: P1, P4, and P6. For P2, the improvement was significant at 3-month follow-up only.

\section{Teacher-reported child anxiety symptoms}

Table 2 shows scores on the three teacher-reported measures: the TRF, the PAS-T and the PSA. Only P6 showed clinical improvement. For the other participants, scores were below the clinical range at all times (even prior to the intervention).

\section{Parental practices and stress}

Table 3 presents the mothers' scores on questionnaires of parental practices and stress. For punitive and inconsistent discipline, the results showed a clinically significant improvement for P2's mother at post-test and at follow-up. For the mother of P5, the change was statistically significant at post-test and at 3-month follow-up. For praises and rewards, the mothers of P1 and $\mathrm{P} 2$ showed changes from the clinical to non-clinical range from pre-test to post-test, and from pre-test to follow-up. The improvement was statistically significant from pre-test to posttest for mother of P3, and from pre-test to follow-up for P1 and P2. For the overprotection scale, four mothers (P1, P2, P5 and P6) showed a statistically significant improvement from pre-test to post-test. For two of these mothers (P1 and P6), the improvement was also statistically significant from pre-test to follow-up. Concerning parental stress, few changes were observed following intervention.

\section{Discussion}

The main purpose of our study was to examine the impact of a parent training programme on separation anxiety symptoms in young children. Improvements in SAD symptoms were 
Table 2. Results on questionnaires completed by the teachers

\begin{tabular}{|c|c|c|c|c|c|c|c|}
\hline Participant & Scale & Pre & Post & $\begin{array}{l}\text { Follow- } \\
\text { up }\end{array}$ & $\begin{array}{l}\text { Clinical } \\
\text { range }\end{array}$ & $\begin{array}{l}\mathrm{RC} \\
\text { index } \\
\text { pre-post }\end{array}$ & $\begin{array}{l}\mathrm{RC} \\
\text { index } \\
\text { pre-follow-up }\end{array}$ \\
\hline \multirow[t]{6}{*}{$\overline{P 1}$} & TRF-ANX & $0^{a}$ & - & $0^{a}$ & 5 & 0.00 & 0.00 \\
\hline & PAS-SAD & $1^{a}$ & - & $0^{a}$ & 3.9 & & \\
\hline & PSA-ADAPT & $317^{a}$ & - & $320^{a}$ & 208 & - & 0.14 \\
\hline & PSA-INTERN & $82^{a}$ & - & $86^{a}$ & 63 & - & 0.46 \\
\hline & PSA-ANXCON & $44^{a}$ & - & $40^{a}$ & 25 & - & -0.68 \\
\hline & PSA-DAUTO & $31^{a}$ & - & $38^{a}$ & 23 & - & 1.60 \\
\hline \multirow[t]{6}{*}{$\mathrm{P} 2$} & TRF-ANX & $2^{a}$ & $0^{a}$ & $0^{a}$ & 6 & -0.97 & -0.97 \\
\hline & PAS-SAD & $1^{a}$ & $0^{a}$ & $0^{a}$ & 3.9 & & \\
\hline & PSA-ADAPT & $317^{a}$ & $340^{a}$ & $336^{a}$ & 235 & 0.23 & 0.91 \\
\hline & PSA-INTERN & $85^{a}$ & $87^{a}$ & $87^{a}$ & 65 & -0.11 & 0.23 \\
\hline & PSI-DISTR & $39^{a}$ & $43^{a}$ & $41^{a}$ & 28 & 0.68 & 0.34 \\
\hline & PSA-DAUTO & $34^{a}$ & $37^{a}$ & $36^{a}$ & 24 & 0.23 & 0.46 \\
\hline \multirow[t]{6}{*}{ P3 } & TRF-ANX & $1^{a}$ & $0^{a}$ & $0^{a}$ & 6 & -0.48 & -0.48 \\
\hline & PAS-SAD & $0^{a}$ & $0^{a}$ & $0^{a}$ & 3.9 & & \\
\hline & PSA-ADAPT & $362^{a}$ & $358^{a}$ & $370^{a}$ & 235 & -0.19 & 0.38 \\
\hline & PSA-INTERN & $95^{a}$ & $90^{a}$ & $96^{a}$ & 65 & -0.57 & 0.11 \\
\hline & PSA-ANXCON & $46^{a}$ & $45^{a}$ & $49^{a}$ & 28 & -0.17 & 0.51 \\
\hline & PSA-DAUTO & $40^{a}$ & $44^{a}$ & $48^{a}$ & 24 & 0.91 & 1.82 \\
\hline \multirow[t]{6}{*}{ P4 } & TRF-ANX & $2^{a}$ & - & $3^{a}$ & 5 & - & 0.48 \\
\hline & PAS-SAD & $1^{a}$ & - & $0^{a}$ & 3.9 & & \\
\hline & PSA-ADAPT & $303^{a}$ & - & $234^{a}$ & 208 & - & -3.30 \\
\hline & PSA-INTERN & $86^{a}$ & - & $66^{a}$ & 63 & - & -2.29 \\
\hline & PSA-ANXCON & $40^{a}$ & - & 25 & 25 & - & -2.53 \\
\hline & PSA-DAUTO & $32^{a}$ & - & $36^{\mathrm{a}}$ & 23 & - & 0.91 \\
\hline \multirow[t]{6}{*}{ P5 } & TRF-ANX & $2^{a}$ & $1^{a}$ & $0^{a}$ & 5 & -0.48 & -0.97 \\
\hline & PAS-SAD & $0^{a}$ & $0^{a}$ & $1^{a}$ & 3.9 & & \\
\hline & PSA-ADAPT & $267^{a}$ & $285^{a}$ & $276^{a}$ & 208 & 0.84 & 0.41 \\
\hline & PSA-INTERN & $81^{a}$ & $81^{a}$ & $88^{a}$ & 63 & -0.06 & 0.75 \\
\hline & PSA-ANXCON & $45^{a}$ & $41^{a}$ & $41^{a}$ & 25 & -0.68 & -0.68 \\
\hline & PSA-DAUTO & $39^{a}$ & $39^{a}$ & $30^{a}$ & 23 & -0.11 & -2.17 \\
\hline \multirow[t]{6}{*}{ P6 } & TRF-ANX & 8 & $3^{a b}$ & $2^{a b}$ & 5 & -2.42 & -2.91 \\
\hline & PAS-SAD & 15 & $2^{a}$ & $1^{a}$ & 3.9 & & \\
\hline & PSA-ADAPT & $276^{a}$ & $299^{a}$ & $286^{a}$ & 208 & 1.10 & 0.96 \\
\hline & PSA-INTERN & 56 & $75^{a b}$ & $81^{a b}$ & 63 & 2.18 & 2.87 \\
\hline & PSA-ANXCON & 23 & $32^{a}$ & $31^{a}$ & $25^{a}$ & 1.52 & 1.35 \\
\hline & PSA-DAUTO & 22 & $34^{a b}$ & $34^{a b}$ & 23 & 2.74 & 2.74 \\
\hline
\end{tabular}

TRF-ANX, Teacher Report Form - Anxiety Problems Scale; PAS-SAD, Preschool Anxiety Scale - Teacher Version - Separation Anxiety Scale; PSA-ADAPT, Socio Affective Profile - General Adaptation Scale; PSA-INTERN, Socio Affective Profile - Internalized Problems Scale; PSAANXCON, Socio Affective Profile - Anxious/Confident Scale; PSA-DAUTO, Socio Affective Profile Dependant/Autonomous Scale. ${ }^{a}$ Score in non-clinical range; ${ }^{b}$ statistically significant change according to RC reliability index. Significant changes $(\geq 1.96)$ are in bold. 
Table 3. Results on questionnaires of parental practices and stress

\begin{tabular}{|c|c|c|c|c|c|c|c|}
\hline Participant & Scale & Pre & Post & $\begin{array}{l}\text { Follow- } \\
\text { up }\end{array}$ & $\begin{array}{l}\text { Clinical } \\
\text { range }\end{array}$ & $\begin{array}{l}\text { RC } \\
\text { index } \\
\text { pre-post }\end{array}$ & $\begin{array}{l}\mathrm{RC} \\
\text { index } \\
\text { pre-follow-up }\end{array}$ \\
\hline \multirow[t]{6}{*}{$\mathrm{P} 1$} & PPI-PUNIT & 3.33 & 2.67 & 2.86 & 2.67 & -1.5 & -1.07 \\
\hline & PPI-PRAISE & 3.6 & $5.2^{a b}$ & $5.4^{a b}$ & 4.27 & 3.7 & 4.17 \\
\hline & PPS-TOTAL & $27^{a}$ & $22^{a b}$ & $20^{a b}$ & 36 & -2.33 & -3.27 \\
\hline & PSI-TOTAL & 91 & $74^{a}$ & $75^{a}$ & 90 & -1.54 & -1.45 \\
\hline & PSI-DISTR & 41 & $21^{a b}$ & $23^{a b}$ & 40.8 & -3.50 & -3.15 \\
\hline & PSI-DYSF & $16^{a}$ & $20^{a}$ & $19^{a}$ & 28.3 & 0.95 & 0.71 \\
\hline \multirow[t]{6}{*}{$\mathrm{P} 2$} & PPI-PUNIT & 2.73 & $2.47^{a}$ & $2.33^{a}$ & 2.67 & -0.59 & -0.91 \\
\hline & PPI-PRAISE & 4 & $4.6^{a}$ & $5.1^{a b}$ & 4.27 & 1.39 & 2.55 \\
\hline & PPS-TOTAL & $31^{a}$ & $24^{a b}$ & $28^{a}$ & 36 & -3.27 & -1.40 \\
\hline & PSI-TOTAL & 103 & 100 & 102 & 90 & -0.27 & -0.09 \\
\hline & PSI-DISTR & 43 & 42 & $39^{a}$ & 40.8 & -0.17 & -0.70 \\
\hline & PSI-DYSF & $25^{a}$ & $23^{a}$ & $27^{a}$ & 28.3 & -0.48 & 0.48 \\
\hline \multirow[t]{6}{*}{ P3 } & PPI-PUNIT & 3 & 2.73 & 2.8 & 2.67 & -0.61 & -0.45 \\
\hline & PPI-PRAISE & $4.3^{a}$ & $5.6^{a b}$ & $5.1^{a}$ & 4.27 & 3.01 & 1.85 \\
\hline & PPS-TOTAL & $21^{a}$ & $22^{a}$ & $21^{a}$ & 32 & 0.47 & 0.00 \\
\hline & PSI-TOTAL & $70^{a}$ & $60^{a}$ & $88^{a}$ & 90 & -0.90 & 1.63 \\
\hline & PSI-DISTR & $21^{a}$ & $17^{a}$ & $24^{a}$ & 40.8 & -0.70 & 0.52 \\
\hline & PSI-DYSF & $22^{a}$ & $25^{a}$ & $28^{a}$ & 28.3 & 0.71 & 1.43 \\
\hline \multirow[t]{6}{*}{$\mathrm{P} 4$} & PPI-PUNIT & 3 & 2.93 & 2.87 & 2.67 & -0.16 & -0.29 \\
\hline & PPI-PRAISE & $5.1^{a}$ & $4.6^{a}$ & $4.3^{a}$ & 4.27 & -1.16 & -1.85 \\
\hline & PPS-TOTAL & $21^{a}$ & $20^{a}$ & $26^{a}$ & 35 & -0.47 & 2.33 \\
\hline & PSI-TOTAL & $75^{a}$ & $72^{a}$ & 100 & 90 & -0.27 & 2.26 \\
\hline & PSI-DISTR & $25^{a}$ & $23^{a}$ & $35^{a}$ & 40.8 & -0.35 & 1.75 \\
\hline & PSI-DYSF & $17^{a}$ & $22^{a}$ & $23^{a}$ & 28.3 & 1.19 & 1.43 \\
\hline \multirow[t]{6}{*}{ P5 } & PPI-PUNIT & 4 & 2.67 & 2.8 & 2.67 & -3.02 & -2.72 \\
\hline & PPI-PRAISE & 3.6 & 3.7 & 3.9 & 4.27 & 0.23 & 0.69 \\
\hline & PPS-TOTAL & $25^{a}$ & $19^{a b}$ & $25^{a}$ & 36 & -2.80 & 0.00 \\
\hline & PSI-TOTAL & 109 & 105 & 98 & 90 & -0.36 & -1.00 \\
\hline & PSI-DISTR & $33^{a}$ & $35^{a}$ & $26^{a}$ & 40.8 & 0.35 & -1.22 \\
\hline & PSI-DYSF & 29 & $27^{a}$ & $28^{a}$ & 28.3 & -0.48 & -0.24 \\
\hline \multirow[t]{6}{*}{ P6 } & PPI-PUNIT & 2.93 & 2.73 & 2.73 & 2.67 & -0.75 & $-0,75$ \\
\hline & PPI-PRAISE & $4.5^{a}$ & $4.9^{a}$ & $4.6^{a}$ & 4.27 & 0.93 & 0.23 \\
\hline & PPS-TOTAL & $29.5^{a}$ & $25^{a b}$ & $24^{a b}$ & 35 & -2.10 & -2.57 \\
\hline & PSI-TOTAL & $76^{a}$ & $69^{a}$ & $70^{a}$ & 90 & -0.63 & -0.54 \\
\hline & PSI-DISTR & $21^{a}$ & $22^{a}$ & $23^{a}$ & 40.8 & 0.17 & 0.35 \\
\hline & PSI-DYSF & $19^{a}$ & $21^{a}$ & $21^{a}$ & 28.3 & 0.48 & 0.48 \\
\hline
\end{tabular}

PPI-PUNIT, Parenting Practices Interview - Punitive and Inconsistent Discipline Scale; PPI-PRAISE, Parenting Practices Interview - Praises and Rewards Scale; PPS-TOTAL, Parent Protection Scale Total Score; PSI-TOTAL, Parental Stress Index - Total Score; PSI-DISTR, Parental Stress Index Distress Scale; PSI-DYSF, Parental Stress Index - Dysfunctional Relation Scale. ${ }^{a}$ Score on a nonclinical range; ${ }^{b}$ statistically significant change according to RC reliability index. Significant changes $(\geq 1.96)$ are in bold. 
observed for four of six children according to the DD completed by the parents. These results were confirmed by changes in ADIS-P: five children no longer met the SAD diagnostic criteria after intervention, and these effects persisted at follow-up. Our results are consistent with those of other studies that have examined the impact of the two programmes adapted in the present study: the PT-SAD (Eisen et al., 2008) and the PCIT (Pincus et al., 2008). Overall, these results support the relevance of intervening only with parents in order to reduce SAD in young children (Cartwright-Hatton et al., 2011; Waters et al., 2009).

For two participants, the programme did not systematically produce the intended effects. At least three factors may explain this observation. First, the frequency of SAD manifestations during baseline may explain some of the lack of observed effects. For P3, only 2-13 occurrences per week were reported by the parents compared with 20-40 for the other children, which provided fewer opportunities to detect significant changes after the introduction of treatment. Second, P3 was the oldest child of the sample. Some of the cognitive components removed from the original programme may have been useful to her: CBT programmes to treat anxiety disorders in children that have been shown to be effective with children 7 years or older typically include cognitive strategies (e.g. Hudson et al., 2009; March et al., 2009).

A third potential explanation for our mixed results is related to the motivation of the parents and to the application of the strategies at home. In the case of P3, exposure exercises were conducted on an irregular basis, less than once a week, with 4 weeks without any practice. P3's avoidance behaviours were related to activities such as sleeping at a friend's house, which were difficult for the parents to organize on a regular basis. Regular and repeated exposure exercises in the treatment of anxiety disorders is an important issue (Blatter-Meunier and Schneider, 2011; Hirshfeld-Becker et al., 2010; Pincus et al., 2008). In contrast, P5's mother was sometimes reluctant to implement the strategies proposed by the programme. For example, she refused to give rewards to her son after exposure exercises because it was inconsistent with her personal values. This explanation would be consistent with Podell and Kendall (2011) who reported that treatment compliance and commitment of parents towards intervention in family CBT treatment for child anxiety was associated to better outcomes.

The changes reported by the parents of $\mathrm{P} 1, \mathrm{P} 2$ and $\mathrm{P} 4$ were not confirmed by the assessment of their teachers. Only the teacher of P6 confirmed the perceptions of the parents and reported significant decreases in the child's general anxiety and SAD as well as an increase in independence. This result could be explained in part by the fact that for P6, the symptoms of SAD occurred mainly when his mother dropped him off at the day care centre. For the other children, the symptoms were observed mainly at home. For all children except P6, the scores reported by teachers were below the clinical range at baseline. Once again, these results may be explained by context specificity in the manifestation of anxiety symptoms. It is also possible that teachers tend to underestimate the symptoms of SAD in children. An alternative explanation could be that the parents overestimated the anxiety symptoms of their child. Studies have shown that parents with anxiety disorders tend to perceive more anxiety in their children (Esbjørn et al., 2014). In the present study, all mothers but one reported past or current episodes of anxiety.

Another objective of this study was to examine changes in parental practices and on parental stress following the parent-training programme. Our results showed some changes in parental behaviours. For example, some mothers increased their use of specific praises and rewards, and showed reductions in negative discipline. The most frequent change was that 
four mothers showed a decrease in their overprotection behaviours following treatment. This result is promising as the treatment was relatively short and few sessions were specifically related to parental practices. That said, we did not observe changes in parental stress. These results are consistent with previous studies, which showed that the family-oriented CBT may improve some parental practices (e.g. overinvolvement), but its effects on parental stress is more limited (Eisen et al., 2008; Esbjørn et al., 2014; Wood et al., 2009). One potential explanation for these results is that programmes designed to modify specific behaviours do not target sources of stress unrelated to the child (e.g. marital distress, employment stress). Furthermore, the original version of the PCIT included a minimum of nine sessions targeting the parent-child relationship, whereas our adapted programme only included two sessions. This discrepancy may explain why we did not observe significant changes in child-related stress in our study.

Our study extends the research literature in several ways. First, the intervention was conceived for a developmental period for which few studies were conducted to date in the treatment of SAD. The programme combines both CBT strategies and a relational component. Another strength of the programme is that it was delivered exclusively to parents. Given that the parents play a crucial role in the development, maintenance and treatment of SAD, their involvement seems essential. Furthermore, the inclusion of measures to assess changes in parental practices and stress has allowed the examination of dimensions often neglected in the research literature. Finally, we also included teacher-reported measures, which extends prior research.

Although the results of our study were promising, it is important to interpret them with caution. For practical reasons related to recruitment, we used a non-concurrent multiple baseline design. This approach is less rigorous than the standard (concurrent) design because the participants do not take part in the assessment and intervention at the same time. Second, even if both parents were encouraged to participate in the assessment and intervention, only one father was present during sessions. Participation of the fathers is unfortunately still rare in family studies for child anxiety disorders. Podell and Kendall (2011) have measured the impact of the implication of mothers and fathers in the treatment of child anxiety. Their results revealed that the implication of both parents predicted a better response to treatment for the child. Similarly, the findings of studies examining maternal and paternal treatment outcome predictors show differential results for mothers and fathers (Liber et al., 2008). The challenge is to find original ways to convince fathers to participate. Fabiano (2007) reviewed the literature on father participation in parent training for attention-deficit hyperactivity disorder (ADHD). Even if his review was not directly concerned with anxiety disorders, his recommendations might be helpful. For example, he suggests reducing stigma associated to clinical services. Because fathers do not typically report problems with parenting, calling an intervention 'parent training' may discourage father participation because the title implies a skills deficit. He also recommended that treatment be implemented in familiar settings (e.g. context of sports activities).

Another limitation is that all mothers had at least a bachelor degree. Thus it is unclear whether less educated mothers would have responded the same to the parent-training programme given its complexity and intensity. Our study may also have a self-selection bias because the mothers responded to advertisements and were not referred by health professionals. A final limitation concerns the absence of direct assessments of each child. We relied mainly on parental reports, which may be biased by their perceptions. Pincus et al. 
(2005) have administered the ADIS and other self-report measures to children as young as 4 years old using several developmental adaptations such as providing reading assistance and using visual aids when necessary. However, we currently have only limited data on the validity of these measures for the assessment of anxiety disorders for children who are as young.

Because our small sample size limits the generalizability of our results, randomized controlled studies are necessary in order to replicate our results and to confirm the efficacy of the programme. Moreover, studies with longer follow-ups should be conducted to examine long-term changes. Conducting a component analysis to identify those that are most effective (e.g. relational component, relaxation techniques) appears relevant. Additional components may be introduced such as cognitive restructuring, strategies for oppositional behaviours that are often related to $\mathrm{SAD}$, or techniques to improve motivation in parents. These strategies may be determined according to specific needs and characteristics of the parents and of the child using a modular approach (Chorpita, 2007). The use of direct observational measures would provide a more thorough examination of the impact of treatment in the future.

Future studies may examine the moderation or mediation effects of factors such as age of the child, comorbid disorders, status of the child in the family (e.g. single child), marital status (e.g. single mother, divorced), and the presence of parental anxiety and depression using group designs. Exploring the impact of the child's independence, sense of control and competence as well as the ability to express emotions as potential mechanisms of change may also further extend the research literature. Future research should examine how family processes (e.g. parental sense of competency, efficacy beliefs) affect child treatment outcomes. To this end, researchers should consider assessing how parents adjust after their children have undergone treatment and what strategies they adopt to promote independence.

\section{Conclusion}

Overall, our results indicate that CBT combined with a parent-child component from the PCIT may be effective in reducing SAD symptoms in young children even when the practitioner does not intervene directly with the child. In our study, having the parent apply the intervention under the supervision of a practitioner was sufficient to produce desirable changes in behaviour in most participants. This approach may prove particularly useful when financial and human resources are limited. Furthermore, involving the parents in the entire process may promote the generalization of the changes to all environments in which the parents are present. That said, our study should be replicated to determine the generalizability of the results in a larger sample.

\section{Main points}

(1) Separation anxiety disorder (SAD) is a prevalent disorder, with a prevalence as high as $10 \%$ among preschool children.

(2) Among risk factors associated with the development of SAD, family factors such as insecure attachment, parental stress and controlling parental practices are important.

(3) Cognitive behaviour therapy (CBT) was found to be the best treatment for childhood anxiety disorders. However, few studies have examined the efficacy of CBT to specifically treat SAD and research on the impact of CBT for SAD in children younger than 7 years old has been very limited. 
(4) We examined the effects of a cognitive parent training programme with six children with SAD aged between 4 and 7 years. A non-concurrent multiple baseline design was used to examine the impact of the treatment. Five of six children no longer met the criteria for SAD diagnosis after treatment and at three-month follow-up.

(5) We also found promising results concerning parental practices. Four mothers reported a decrease in overprotection following their participation in the programme.

\section{Acknowledgements}

The first author has received a fellowship from The Fonds de recherche du Québec - Santé (FRQS), as well as a fellowship from the Department of Psychology of the University of Montreal.

\section{Ethical statement}

All the authors of the present article have abided by the Ethical principles of research as set out by the American Psychiatric Association. Ethical approval was provided by the Ethics Committee of the Department of Psychology (Arts and Science Faculty) at the University of Montreal, where the study was conducted.

\section{Conflicts of interest}

Sandra Mayer-Brien, Lyse Turgeon and Marc Lanovaz have no conflicts of interest with respect to this publication.

\section{Financial support}

This research received no specific grant from any funding agency, commercial of not-for-profit sectors.

\section{Recommended follow-up reading}

Eisen AR, Sussman JM, Schmidt T, Mason L, Hausler LA, Hashim R (2011). Separation anxiety disorder. In Handbook of Child and Adolescent Anxiety disorders (ed. D. McKay and E. A. Storch), pp. 245-259. doi: 10.1007/978-1-4419-7784-7_17

\section{References}

Abidin RR (1995). Parenting Stress Index: Professional Manual (3rd edition). Odessa, FL: Psychological Assessment Resources.

Achenbach TM, Rescorla LA (2001). Manual for the ASEBA School-Age Forms and Profiles. Burlington: University of Vermont, Research Center for Children, Youth and Families.

American Psychiatric Association (2000). Diagnostic and Statistical Manual of Mental Disorders (4th edition, text revision). Washington, DC: American Psychiatric Association.

American Psychiatric Association (2013). Diagnostic and Statistical Manual of Mental Disorders (5th edition). Arlington, VA: American Psychiatric Association. 
Barlow DH, Nock M K, Hersen M (2009). Single Case Experimental Designs: Strategies for Studying Behavior Change (3rd edition). Boston: MA, Pearson Education.

Barrett PM, Lowry-Webster H, Turner CM (1999). FRIENDS for Children Group Leader Manual. Brisbane, Australia: Australian Academic Press.

Barrett PM, Rapee RM, Dadds MM, Ryan SM (1996). Family enhancement of cognitive style in anxious and aggressive children. Journal of Abnormal Child Psychology 24, 187203.

Biederman J, Petty CR, Hirshfeld-Becker DR, Henin A, Faraone SV, Fraire M et al. (2007). Developmental trajectories of anxiety disorders in offspring at high risk for panic disorder and major depression, Psychiatry Research 143, 245-252. doi: 10.1016/j.psychres.2007.02.016

Bigras M, LaFreniere PJ, Abidin RR (1996). Indice de stress parental: Manuel francophone en complément à l'édition américaine [Parental Stress Index. French manual to complement the American edition]. New York, NY: Multi-Health Systems.

Blatter-Meunier J, Schneider S (2011). Thérapie comportementale-cognitive des troubles émotionnels liés à l'anxiété de séparation. Journal de thérapie comportementale et cognitive 21, 84-89. doi: 10.1016/j.jtcc.2011.07.011

Bögels SM, Brechman-Toussaint ML (2006). Family issues in child anxiety: attachment, family functioning, parental rearing and beliefs. Clinical Psychology Review 26, 834-856. doi: 10.1016/j.cpr.2005.08.001

Broeren S, Muris P (2008). Psychometric evaluation of two new parent-rating scales for measuring anxiety symptoms in young Dutch children. Journal of Anxiety Disorders 22, 949-958. doi: 10.1016/j.janxdis.2007.09.008

Brinkmeyer MY, Eyberg SM (2003). Parent-child interaction therapy for oppositional children. In Evidence-Based Psychotherapies for Children and Adolescents (ed. A. E. Kazdin and J. R. Weisz), pp. 204-223. New York, NY: Guilford Press.

Brumariu LE, Kerns KA (2010a). Mother-child attachment patterns and different types of anxiety symptoms: is there specificity of relations? Child Psychiatry and Human Development 41, 663-674. doi: 10.1007/s10578-010-0195-0

Brumariu LE, Kerns KA (2010b). Parent-child attachment and internalizing symptoms in childhood and adolescence: a review of empirical findings and future directions. Development and Psychopathology 22, 177-203. doi: 10.1017/S0954579409990344

Carter AS, Wagmiller RJ, Gray SAO, McCarthy KJ, Horwitz SM, Briggs-Gowan MJ (2010). Prevalence of DSM-IV disorders in a representative, healthy birth cohort at school entry: sociodemographic risks and social adaptation. Journal of the American Academy of Child and Adolescent Psychiatry 49, 686-698.

Cartwright-Hatton S, McNally D, Field AP, Stewart R, Laskey B, Dixon C et al. (2011). A new parenting-based group intervention for young anxious children: results of a randomized control trial. Journal of the American Academy of Child and Adolescent Psychiatry 50, 242-251. e6. doi:10.1016/j.jaac.2010.12.015

Chase RM, Pincus DB (2011). Sleep-related problems in children and adolescent with anxiety disorders. Behavioral Sleep Medicine 9, 224-236. doi: 10.1080/15402002.2011.606768

Choate ML, Pincus DB (2001). The Weekly Record of Anxiety at Separation: A Home Monitoring Measure for Parents. Unpublished manuscript, Boston University Center for Anxiety and Related Disorders.

Choate ML, Pincus DB, Eyberg SM, Barlow DH (2005). Parent-child interaction therapy for treatment of separation anxiety disorder in young children: a pilot study. Cognitive and Behavioral Practice 12, 126-135. doi:10.1016/S1077-7229(05)80047-1

Chorpita BF (2007). Modular Cognitive-Behavioral Therapy for Childhood Anxiety Disorders. New York, NY: Guilford Press. 
Costa NM, Weems CF, Pellerin K, Dalton R (2006). Parenting stress and childhood psychopathology: an examination of specificity to internalizing and externalizing symptoms. Journal of Psychopathology and Behavioral Assessment 28, 113-122. doi: 10.1007/s10862-006-7489-3

de la Barra F, Vicente B, Saldivia S, Melipillan R (2014). Separation anxiety, social phobia and generalized anxiety disorders in the Chilean epidemiological study of children and adolescents. Journal of Child and Adolescent Behavior 2, 1-7. doi: 10.4172/jcalb.1000133

Dumas JE, LaFreniere PJ, Capuano F, Durning P (1997). Profil Socio-Affectif(PSA): Évaluation des compétences sociales et des difficultés d'adaptation des enfants de 2 ans $1 / 2$ à 6 ans. Paris, France: Éditions du Centre de Psychologie Appliquée.

Ehrenreich JT, Santucci LC, Weiner CL (2008). Separation anxiety disorder in youth: phenomenology, assessment and treatment. Psichologia Conducta 16, 389-412. doi: 10.1901/jaba.2008.16-389.

Eisen AR, Raleigh H, Neuhoff CC (2008). The unique impact of parent training for separation anxiety disorder in children. Behavior Therapy 39, 195-206. doi: 10.1016/j.beth.2007.07.004

Esbjørn BH, Sømhovd MJ, Nielsen SK, Normann N, Leth I, Reinholdt-Dunne M (2014). Parental changes after involvement in their anxious child's cognitive behavior therapy. Journal of Anxiety Disorders 28, 664-670. doi: 10.1016/j.janxdis.2014.07.008

Figueroa A, Soutullo C, Ono Y, Saito K (2012). Separation anxiety. In IACACAP eTextbook of Child and Adolescent Mental Health (ed. J. M. Rey), pp.1-24. Retrieved from: http://iacapap.org/wp-content/uploads/F.2-SEPARATION-ANXIETY-300812.pdf

Fisher WW, Kelley ME, Lomas JE (2003). Visual aids and structured criteria for improving visual inspection and interpretation of single-case designs, Journal of Applied Behavior Analysis 36, 388406. doi: 10.1901/jaba.2003.36-387

Fabiano GA (2007). Father participation in behavioral parent training for ADHD: review and recommendations for increasing inclusion and engagement. Journal of Family Psychology 21, 683693.

Franz L, Angold A, Copeland W, Costello EJ, Towe-Goodman N, Egger H (2013). Preschool anxiety disorders in pediatric primary care: prevalence and comorbidity. Journal of the American Academy of Child and Adolescent Psychiatry 52, 1294-1303. doi: 10.1016/j.jaac.2013.09.008

Hirshfeld-Becker DR, Masek B, Henin A, Blakely LR, Pollock-Wurman RA, McQuade J et al. (2010). Cognitive behavioral therapy for 4- to 7-year-old children with anxiety disorders: a randomized clinical trial. Journal of Consulting and Clinical Psychology 78, 498-510. doi: 10.1037/a0019055

Hudson JL, Doyle AM, Gar N (2009). Child and maternal influence on parenting behavior in clinically anxious children. Journal of Clinical Child and Adolescent Psychology 38, 256-262. doi: 10.1080/15374410802698438

Jacobson NS, Truax P (1991). Clinical significance: a statistical approach to defining meaningful change in psychotherapy research. Journal of Consulting and Clinical Psychology 59, 12-19. doi: 10.1037/0022-006X.59.1.12

Kearny CA, Sims KE, Pursell CR, Tillotson CA (2003). Separation anxiety disorder in young children: a longitudinal and family analysis. Journal of Clinical Child and Adolescent Psychology 32, 593-598.

Last CG, Francis K, Hersen M, Kazdin AE, Strauss CC (1987). Separation anxiety and school phobia: a comparison using DSM-III criteria. American Journal of Psychiatry 144, 653-657.

Lavigne JV, LeBailly SA, Hopkins J, Gouze KR, Binns HJ (2009). The prevalence of ADHD, ODD, depression and anxiety in a community sample of 4-year-olds. Journal of Clinical Child and Adolescent Psychology 38, 315-328. doi: 10.1080/15374410902851382

Lessard J (2010). Les pratiques éducatives parentales: Le point de vue des parents et d'un observateur [Parental educative practives. Parents' and Observers' point of view]. Doctoral dissertation, University of Montreal. Retrieved from: https://papyrus.bib.umontreal.ca 
Lewinsohn PM, Holm-Denoma JM, Small JW, Seeley JR, (2008). Separation anxiety disorder in childhood as a risk factor for future mental illness. Journal of American Academy of Child and Adolescent Psychiatry 47, 548-555. doi: 10.1097/CHI.0b013e31816765e7

Liber JM, van Widenfelt BM, Goedhart AW, Utens EMWJ, van der Leeden AJM, Markus MT, Treffers PDA (2008). Parenting and parental anxiety and depression as predictors of treatment outcomes for childhood anxiety disorders. Has the role of fathers been underestimated? Journal of Clinical Child and Adolescent Psychology 37, 747-758. doi: 10.1080/15374410802359692

March S, Spence SH, Donovan CL (2009). The efficacy of an internet-based cognitive-behavioral therapy approach to the treatment of child anxiety disorders. Journal of Pediatric Psychology 34, 474-487. doi: 10.1093/jpepsy/jsn099

McLeod BD, Wood JJ, Avny SB (2011). Parenting and child anxiety disorders. In Handbook of Child and Adolescent Anxiety Disorders (ed. D. McKay and E. A. Storch), pp. 213-228. doi: 10.1007/978-1-4419-7784-7_15

Mofrad S, Abdullah R, Samah BA (2009). Perceived parental overprotection and separation anxiety: does specific parental rearing serve as specific risk factor? Asian Social Science 5, 109-119.

Mofrad S, Abdullah R, Uba I (2010). Attachment patterns and separation anxiety symptom. Asian Social Science 6, 148-153.

Pahl KM, Barrett PM, Gullo MJ (2012). Examining potential risk factors for anxiety in early childhood. Journal of Anxiety Disorders 26, 311-320. doi: 10.1016/j.janxdis.2011.12.013

Pincus DB, Eyberg SM, Choate ML (2005). Adapting Parent-Child Interaction Therapy for young children with separation anxiety disorder. Education and Treatment of Children 28, 163-181.

Pincus DB, Santucci LC, Ehrenreich JT, Eyberg SM (2008). The implementation of Modified Parent-Child Interaction Therapy for youth with separation anxiety disorder. Cognitive and Behavioral Practice 15, 118-125. doi: 10.1016/j.cbpra.2007.08.002

Podell JL, Kendall PC (2011). Mothers and fathers in family cognitive-behavioral therapy for anxious youth. Journal of Child and Family Studies 20, 182-195. doi: 10.1007/s10826-010-9420-5

Raleigh H, Brien LK, Eisen AR (2002). Parent Training Treatment Manual for Separation Anxious Children. Unpublished manuscript. Farleigh Dickinson University, Teaneck, NJ.

Reynolds S, Wilson C, Austin J, Hooper L. (2012). Effects of psychotherapy for anxiety in children and adolescents: a meta-analytic review. Clinical Psychology Review 32, 251-262.

Santucci LC, Ehrenreich-May J (2013). A randomized control trial of the Child anxiety multi-day program (CAMP) for separation anxiety disorder. Child Psychiatry and Human Development 44, 439-461. doi: 10.1007/s10578-012-0338-6

Santucci LC, Ehrenreich JT, Trosper SE, Bennett SM, Pincus DB (2009). Development and preliminary evaluation of a one-week summer treatment program for separation anxiety disorder. Cognitive and Behavioral Practice 16, 317-331. doi: 10.1016/j.cbpra.2008.12.005

Schneider S, Blatter-Meunier J, Herren C, Adornetto C, In-Albon T, Lavallee K (2011). Disorder-specific cognitive-behavioral therapy for separation anxiety disorder in young children: a randomized waiting-list-controlled trial. Psychotherapy and Psychosomatics 80, 206-215. doi: $10.1159 / 000323444$

Shear K, Jin R, Ruscio AM, Walters EE, Kessler RC (2006). Prevalence and correlates of estimated DSM-IV child and adult separation anxiety disorder in the National Comorbidity Survey Replication. American Journal of Psychiatry 163, 1074-1083. doi: 10.1176/appi.ajp.163.6.1074

Silverman WK, Albano AM (1996). The Anxiety Disorders Interview Schedule for DSM-IV: Child and Parent versions. San Antonio, TX: Psychological Corporation.

Silverman WK, Pina AA, Viswesvaran C (2008). Evidence-based psychosocial treatments for phobic and anxiety disorders in children and adolescents. Journal of Clinical Child and Adolescent Psychology 37, 105-130. 
Silverman WK, Saavedra LM, Pina AA (2001). Test-retest reliability of anxiety symptoms and diagnoses with the Anxiety Disorders Interview Schedule for DSM-IV: Child and Parent versions. Journal of the American Academy of Child and Adolescent Psychiatry 40, 937-944. Retrieved from: http://journals.lww.com/jaacap

Simon E, Dirksen C, Bögels S, Bodden D (2012). Cost-effectiveness of child-focused and parentfocused interventions in a child anxiety prevention program. Journal of Anxiety Disorders 26, 287296.

Smith AM, Flannery-Schroeder EC, Gorman KS, Cook N (2014). Parent cognitive-behavioral intervention for the treatment of childhood anxiety disorders: a pilot study. Behaviour Research and Therapy 61, 156-161.

Spence SH, Rapee R (1999). Preschool Anxiety Scale (Parent Report and Teacher version). Retrieved from: http://www.scaswebsite.com/docs/scas-preschool-scale.pdf

Spence SH, Rapee R, McDonald C, Ingram M (2001). The structure of anxiety symptoms among preschoolers. Behaviour Research and Therapy 39, 1293-1316. doi: 10.1016/S0005-7967(00)00098-X

Swoboda CM, Kratochwill TR, Levin JR (2010). Conservative dual-criterion for single-case research: a guide for visual analysis of $A B, A B A B$, and multiple-baselines designs. (WCER Working Paper no. 2010-13). Retrieved from University of Wisconsin-Madison, Wisconsin Center for Education Research website: http://www.wcer.wisc.edu/publications/workingPapers/papers.php

Thomas JC, Truax P (2008). Assessment and analysis of clinically significant change. In Handbook of Research Methods in Abnormal and Clinical Psychology (ed. D. McKay), pp. 317-335. Thousand Oaks, CA: Sage.

Thomasgard M, Metz WP, Edelbrock C, Shonkoff JP (1995). Parent-child relationship disorders. Part I. Parental overprotection and the development of the Parent Protection Scale. Journal of Developmental and Behavioral Pediatrics 16, 244-250.

Turgeon L, Brousseau L (2001). Entrevue d'évaluation des troubles anxieux chez les enfants et les adolescents pour le DSM-IV (ADIS-C-P). [Anxiety Disorders Interview Schedule for Children and Adolescents for DSM-IV]. Unpublished manuscript. Fernand-Seguin Research Center, Louis-H. Lafontaine Hospital, Montreal, Canada.

Turgeon L, Brousseau L. (2002). Questionnaire sur l'anxiété à l'âge préscolaire [Preschoool Anxiety Questionnaire]. Unpublished manuscript. Fernand-Seguin Research Center, Louis-H. Lafontaine Hospital, Montreal, Canada.

Venet M, Bigras M, Normandeau S (2002). Les qualités psychométriques du PSA-A/The psychometric qualities of the PSA-A [French version of the Socio-Affective Profile]. Canadian Journal of Behavioural Science/Revue canadienne des sciences du comportement 34, 163-167.

Waters AM, Ford LA, Wharton TA, Cobham VE (2009). Cognitive-behavioural therapy for young children with anxiety disorders: comparison of a child + parent condition versus a parent only condition. Behaviour Research and Therapy 47, 654-662. doi: 10.1016/j.brat.2009.04.008

Webster-Stratton C (1998). Preventing conduct problems in Head Start children: strengthening parenting competencies. Journal of Consulting and Clinical Psychology 66, 715-730.

Wood JJ (2006). Parental intrusiveness and children's separation anxiety in a clinical sample. Child Psychiatry of Human Development 37, 73-87.

Wood JJ, McLeod BD, Piacentini JC, Sigman M (2009). One-year follow-up of family versus child CBT for anxiety disorders: exploring the roles of child age and parental intrusiveness. Child Psychiatry and Human Development 40, 301-316. doi: 10.1007/s10578-009-0127-z.

Wood JJ, McLeod BD, Sigman M, Hwang WC, Chu BC (2003). Parenting and childhood anxiety: theory, empirical findings, and future directions. Journal of Child Psychology and Psychiatry 44, 134-151. doi: 10.1111/1469-7610.00106

Wood JJ, Piacentini JC, Bergman L, McCracken J, Barrios V (2002). Concurrent validity of the anxiety disorders section of the Anxiety Disorders Schedule for DSM-IV: Child and 
Parent versions. Journal of Clinical Child and Adolescent Psychology 31, 335-342. doi: 10.1207/S15374424JCCP3103_05

Wood JJ, Piacentini JC, Southam-Gerow M, Chu BC, Sigman M (2006). Family cognitivebehavioral therapy for child anxiety disorders. Journal of the American Academy of Child and Adolescent Psychiatry 45, 314-321.

\section{Learning objectives}

By the end of this paper, the reader should be able to:

(1) Describe the role of parents in the development, maintenance and treatment of separation anxiety disorder in children.

(2) Explain the most recent findings in parent training programmes for the treatment of separation anxiety disorder in children.

(3) Explain the relevance of using single-case designs in the clinical study of separation anxiety disorder. 
Appendix. Daily Diary of Separation Anxiety Symptoms

Instructions: Please indicate the number of times your child showed the following behaviours on each day of the week. For each behaviour, record the distress showed by your child on a scale ranging from 0 to $8(0=$ no distress, $8=$ severe distress $)$ as well as the degree of interference with your daily functioning $(0=$ no impact on our activities, $8=$ we were not able to do our activities $)$.

\begin{tabular}{|c|c|c|c|c|c|c|c|c|c|c|c|c|c|c|c|c|c|c|c|c|c|}
\hline Day & & & & & & & & & & & & & & & & & & & & & \\
\hline $\begin{array}{c}\text { Behaviours } \\
\text { related to } \\
\text { separation } \\
\text { anxiety }\end{array}$ & \# & $\begin{array}{c}\text { Distress } \\
(0-8)\end{array}$ & $\begin{array}{c}\text { Inter- } \\
\text { ference } \\
(0-8)\end{array}$ & \# & $\begin{array}{c}\text { Distress } \\
(0-8)\end{array}$ & $\begin{array}{c}\text { Inter- } \\
\text { ference } \\
(0-8)\end{array}$ & \# & $\begin{array}{c}\text { Distress } \\
(0-8)\end{array}$ & $\begin{array}{c}\text { Inter- } \\
\text { ference } \\
(0-8)\end{array}$ & \# & $\begin{array}{c}\text { Distress } \\
(0-8)\end{array}$ & $\begin{array}{c}\text { Inter- } \\
\text { ference } \\
(0-8)\end{array}$ & \# & $\begin{array}{c}\text { Distress } \\
(0-8)\end{array}$ & $\begin{array}{c}\text { Inter- } \\
\text { ference } \\
(0-8)\end{array}$ & \# & $\begin{array}{c}\text { Distress } \\
(0-8)\end{array}$ & $\begin{array}{c}\text { Inter- } \\
\text { ference } \\
(0-8)\end{array}$ & \# & $\begin{array}{c}\text { Distress } \\
(0-8)\end{array}$ & $\begin{array}{c}\text { Inter- } \\
\text { ference } \\
(0-8)\end{array}$ \\
\hline Symptoms of $s$ & rati & anxiety $\mathrm{re}$ & ted to $d z$ & $\mathrm{car}$ & & & & & & & & & & & & & & & & & \\
\hline $\begin{array}{l}\text { Refused to go to } \\
\text { day care and to } \\
\text { be separated } \\
\text { from his parent }\end{array}$ & & & & & & & & & & & & & & & & & & & & & \\
\hline $\begin{array}{l}\text { Left the day care } \\
\text { before the end o } \\
\text { the day to be } \\
\text { with his parents }\end{array}$ & & & & & & & & & & & & & & & & & & & & & \\
\hline Symptoms of $s$ & rati & anxiety re & ted to th & par & leaving & & & & & & & & & & & & & & & & \\
\hline $\begin{array}{l}\text { Cried/showed } \\
\text { distress before } \\
\text { the parent } \\
\text { leaving }\end{array}$ & & & & & & & & & & & & & & & & & & & & & \\
\hline $\begin{array}{l}\text { Complaints of } \\
\text { physical } \\
\text { sickness before } \\
\text { the parent } \\
\text { leaving }\end{array}$ & & & & & & & & & & & & & & & & & & & & & \\
\hline $\begin{array}{l}\text { Cried/showed } \\
\text { distress when } \\
\text { the parent left }\end{array}$ & & & & & & & & & & & & & & & & & & & & & \\
\hline Symptoms of $s$ & rati & anxiety re & ted to $\mathrm{pl}$ & yor & her activiti & & & & & & & & & & & & & & & & \\
\hline $\begin{array}{l}\text { Refused to play } \\
\text { without the } \\
\text { parent near him }\end{array}$ & & & & & & & & & & & & & & & & & & & & & \\
\hline
\end{tabular}


Appendix. Continued

\begin{tabular}{|c|c|c|c|c|c|c|c|c|c|c|c|c|c|c|c|c|c|c|c|c|c|}
\hline \multicolumn{22}{|l|}{ Day } \\
\hline $\begin{array}{l}\text { Behaviours related } \\
\text { to separation } \\
\text { anxiety }\end{array}$ & \# & \begin{tabular}{|l|}
$\begin{array}{c}\text { Distress } \\
(0-8)\end{array}$ \\
\end{tabular} & $\begin{array}{l}\text { Inter- } \\
\text { ference } \\
(0-8)\end{array}$ & \# & $\begin{array}{c}\text { Distress } \\
(0-8)\end{array}$ & \begin{tabular}{|c|} 
Inter- \\
ference \\
$(0-8)$ \\
\end{tabular} & \# & \begin{tabular}{c|c} 
Distress \\
$(0-8)$
\end{tabular} & $\begin{array}{l}\text { Inter- } \\
\text { ference } \\
(0-8)\end{array}$ & \# & \begin{tabular}{|c|} 
Distress \\
$(0-8)$
\end{tabular} & \begin{tabular}{|c|}
$\begin{array}{l}\text { Inter- } \\
\text { ference } \\
(0-8) \\
\end{array}$ \\
\end{tabular} & \# & \begin{tabular}{|c|} 
Distress \\
$(0-8)$
\end{tabular} & \begin{tabular}{|c|} 
Inter- \\
ference \\
$(0-8)$ \\
\end{tabular} & \# & \begin{tabular}{|c|} 
Distress \\
$(0-8)$
\end{tabular} & \begin{tabular}{|c|}
$\begin{array}{l}\text { Inter- } \\
\text { ference } \\
(0-8) \\
\end{array}$ \\
\end{tabular} & \# & $\begin{array}{c}\text { Distress } \\
(0-8)\end{array}$ & $\begin{array}{c}\text { Inter- } \\
\text { ference } \\
(0-8)\end{array}$ \\
\hline \multicolumn{22}{|c|}{ Symptoms of separation anxiety related to bedtime } \\
\hline \multicolumn{22}{|l|}{$\begin{array}{l}\text { Slept in the } \\
\text { parents' bed }\end{array}$} \\
\hline \multicolumn{22}{|l|}{$\begin{array}{l}\text { Refused to sleep } \\
\text { without a parent in } \\
\text { his room }\end{array}$} \\
\hline \multicolumn{22}{|l|}{$\begin{array}{l}\text { Woke up his } \\
\text { parents during } \\
\text { night }\end{array}$} \\
\hline \multicolumn{22}{|l|}{$\begin{array}{l}\text { Had nightmares } \\
\text { concerning } \\
\text { separation }\end{array}$} \\
\hline \multicolumn{22}{|c|}{ Symptoms of separation anxiety related to staying with parent } \\
\hline \multicolumn{22}{|c|}{\begin{tabular}{l|l|l|l|l|l}
$\begin{array}{l}\text { Followed the parent } \\
\text { all day }\end{array}$ & & & & \\
\end{tabular}} \\
\hline \multirow{2}{*}{\multicolumn{22}{|c|}{\begin{tabular}{|l|l|l|l|}
$\begin{array}{l}\text { Refused to stay } \\
\text { alone without a } \\
\text { parent }\end{array}$ & & & \\
Symptoms of separation anxiety related to the parent's well-being \\
\end{tabular}}} \\
\hline & & & & & & & & & & & & & & & & & & & & & \\
\hline \multicolumn{22}{|l|}{$\begin{array}{l}\text { something bad may } \\
\text { happen to his } \\
\text { parent }\end{array}$} \\
\hline $\begin{array}{l}\text { Symptoms of separ } \\
\text { Whried that st }\end{array}$ & io & inxiety relate & d to the $c$ & ild's & tell-being & & & & & & & & & & & & & & & & \\
\hline $\begin{array}{l}\text { Worried that } \\
\text { something bad may } \\
\text { happen to him }\end{array}$ & & & & & & & & & & & & & & & & & & & & & \\
\hline
\end{tabular}

Adapted from The Weekly Record of Anxiety Separation (WRAS) developed by Molly L. Choate and Donna B. Pincus, Boston University Center for Anxiety and Related Disorders. Reproduced by Eisen, A. R. and Schaeffer, C. E. (2005). Copyright 2001 by Molly L. Choate and Donna B. Pincus. 